\title{
Application of English Language Strategies in International Business Negotiation
}

\author{
Lin-Jing SONG
}

School of Foreign Languages, Nanyang Institute of Technology, Nanyang, Henan

smilingalison@126.com

Keywords:International business negotiation,Business English,Language strategy.

\begin{abstract}
English, as a universal official language and numerous enterprises' negotiation language, plays a vital role in international negotiations. And the use of English language skills often determines the negotiations' success. This paper chooses English language skills in international business negotiations as the research object. It first outlines the theory of international business negotiation, and then demonstrates the importance of using English language skills in international business negotiations. At last, with abundant examples, the essay studies the specific application of English language skills in international business negotiations so as to help the negotiators achieve their planned negotiation goals.
\end{abstract}

\section{Introduction}

In order to ensure perfect achievements in the negotiations, there are three problems we must make it clear in advance: What is international business negotiations? What is the characteristic of international business negotiations? What is the characteristic of business negotiations' language? Only these problems are clear, can we place ourselves in active position.

International business negotiation is a continuous coordinated procedure that takes place between two person or related organizations and groups. On behalf of different countries, the two parties communicate the differences, propose their own scheme, consult on the specific trade issues, and finally reach a mutually satisfactory agreement.

The characteristics of international business negotiations usually possess the features of general business negotiations, and also have the particularity of the international economic activity, which are reflected as follows:

Bearing Strong Political Nature: International business negotiation is not only a kind of business negotiation, but also an international exchange activity with strong political nature. Business relationship between the two sides, as an integral part of the economic relations between the two countries and regions, often involves political relations and diplomatic relations.

Basing on the International Commercial Law: As the international business negotiation results will lead to international transfer of assets, it must involve international trade, international settlement, international insurance, international transport and a series of problems. Therefore, negotiations in the international business must base on international commercial law, and use international practice as the foundation.

Following the Principle of Equality and Mutual Benefits:In international business negotiations, negotiators should adhere to the principle of equality and mutual benefits, donot foist one's opinions upon others or accept unequal conditions.

Having Great Difficulty: The international business negotiators representing the interests of different countries and regions own different social, cultural, economic and political background, and their values, ways of thinking, behavior, language and customs are also quite different from each other. Therefore, the influential factors of negotiation are more complex and difficult.

Generally speaking, the language of business negotiation should have the following basic features: objectivity, orientation, logicality and normalization.

Objectivity: The objectivity of language mainly shows that: describing the present situation of the enterprise must conform to the reality; describing the quality of the goods and function should 
according to the basis of reality; if there is a chance you'd better show the samples or demonstrate it on the spot. Your quotation should be reasonable, and it should not only meet your own needs, but also consider the other party's benefits. As for the terms of payment, you may consider the other party's requirements, but it must be accepted by both sides.

Orientation: The orientation of the language is that the language should focus on the specific themes and has an exact target. Negotiation language should be a direct reply to the other party's question.

Logicality: The logicality refers to that the negotiator's language should comply with the rule of logic, expressing ideas clearly, making correct judgment and being cautious about wording.

Normalization: The normalization means that the language should be expressed politely and clearly, strictly and exactly.

\section{Importance of English Language Strategies' Application in International Business Negotiation}

The essence of business negotiation is the negotiators use language to communicate, contact and achieve the expected win-win situation. English language skills play a bridge role in the commercial negotiations, whether we can use negotiation language art well or not determines the success or failure of the negotiation.

English is an important medium for exchanging informationin negotiation. In the background of global economic integration, the role of language is obvious, especially Business English. It has not only become the most commonly used means of communication in business activity, but also plays the role of information carrier.

Business negotiation is a direct communication activity between businessmen. In this kind of activity, negotiators'quality, ability, experience and mental state all have great impact on the negotiating process and results. These features allow business negotiations to have some unpredictable characteristics, and difficult to grasp. Even if the negotiations have the same content, the same environment and conditions, different people negotiate, the result is often different. This shows that the negotiation has its strategies.Therefore, for negotiators in the negotiations they should not only pay attention to science but also attach importance to language skills. "Science" is the guiding thought, guiding the negotiators to make correct negotiation strategies, and the "skill" is a necessary factor for negotiation strategies' implementation. Any business negotiations cannot be done without the use of negotiation strategies, and it directly influences the whole business negotiations, and act on the results. In business negotiations, in addition to the language politeness, enunciation, and fluency these general requirements, negotiators should also pay attention to language strategies, since using them skillfully can promote the success of the negotiations.

\section{Application of English Language Strategies in International Business Negotiation}

International business negotiation is completed in the exchange of information through negotiations between the two parties, and information transmission and reception is done through negotiations via stating, questioning, replaying and so on. In order to complete the task smoothly in negotiations, understanding and grasping stating, questioning, replaying language strategies plays a key role in helping the negotiators win the success.

\section{English Statement Strategy}

Statement strategy includes the strategy of entering into topic and the stating strategy.

\section{Strategy of Entering into Topic}

In the business negotiations, negotiators must have strategies of entering into question and adopting the proper way: Firstly, the method of circuitous entering into question, for example, you can talk about your company's situations. Secondly, you can talk about some details, and then talk about the principles. Only focusing on the important principles will make people feel nervous, so at first you can talk about the specific details to make the negotiation peaceful and create a good 
atmosphere for the next negotiation. Thirdly, you can talk about general principle and then talk about some details. Fourthly, you can start from the specific topics and ask some questions. The following is a specific example of the negotiation:

Jany: Ah, Lina and Lucy.Welcome. It’s a pleasure to see you here again. Now, you know everyone here, except for Andy.

Lina: How do you do?

Andy: How do you do?

Lucy: A pleasure.

Jany: Andy is our business manager. He’ll be sitting in. Can we get you anything? Tea or coffee?

Lucy: No, thank you.

Lina: We're fine, thanks.

Jany: All right then. Please, take a seat. I know your time is valuable. We hope that this meeting won't go longer than an hour. Would you like me to arrange a taxi for you when we finish?

Lina: Thank you. That would be great.

Jany: I'll make a note of it. I have an agenda drawn up but feel free to change the order or add items as you wish.

Lina: This looks fine. You seem to have covered everything.

In this conversation, Jany first introduced the related people who participate in the negotiations, and then served tea, also as the host, she asked the other party's travel, accommodation, making guests feel at home. This reflects the company's sincerity, and can also create a good atmosphere for cooperation and negotiation, thus can be regarded as a good example.

\section{Stating Strategy}

In the process of public issues, first of all, you should be clear of this conversation topic, so as to focus each other's attention on the topic, and try to reach an agreement. Secondly, you have to demonstrate that you have got economic interests from this conversation and show your basic position. You can display the economic interests of the previous cooperation between the two sides; show that your business reputation has been approved by the customer. Thirdly, in the description of the relevant negotiations, language should be concise, correct, and easy to understand, and seize the key points. Finally, you must know the purpose of the description is to let others understand your intentions, and create good atmosphere of negotiations. Therefore, the description should be authentic, simple and easy to understand.

If the other party begins to state the problem, you must listen to their views, summarize the opinions, and try to understand the content of description. In order to avoid misunderstanding, you must try to think and understand the essence of their statement. If the content of the statement conflicts with yours, you can interrupt, but should not immediately arouse dispute with rivals. When they finish talking, you can find another way to present your ideas. Statements should conform to the reality, promote friendly cooperation, and you have to be honest with customers. You must learn to observe the reaction of the other party, and then adjust your conversation, pronunciation and intonation, adapt to other's changes, the following example well illustrates how to correctly grasp the situation to achieve goals in international business negotiations.

An American company representative sold an oxygen-free copper host combination oven to one of our cable factory, its price ranged from $\$ 2200000$ to $\$ 1500000$, down to $\$ 1300000$. Seeing Chinese representative still cannot strike a deal and sign the contract they shouted,"You have no sincerity, we cannot continue!" Our representative says, "This high price reflects you have no sincerity, we did not want to talk with you anymore.” The American party saw China cannot sit down again for negotiations, and set an ultimatum,"1200000, no further concession!”As a result, it leads to the fail of the negotiation. The American representative took the booked ticket and had a farewell meeting with the Chinese company. The Chinese representative took out the data that the American party sold the same oven to Hungary two years ago at the price of $\$ 950000$ and showed it to them. "It was two years ago, and now the price will naturally rose," the American party exclaimed. "No," the representative of China counter,"the inflation index is 6\% per year, according 
to the calculation, the price should be 1067000 dollars." The American representatives at this time were astonished, and finally sold the oven for $\$ 1070000$.

In this case, the two sides eventually struck a deal at the price of $\$ 1070000$. At the beginning of the negotiation, as the American representatives did not tell the rising prices to Chinese representatives, it led to the initial failure of the negotiation, then the deal was struck at a reluctant price in the last time. The United States should pay attention to the use of language and make themselves fully understood, and their expression should be simple and seize the key points. They also should pay attention to the tone, rhythm, sound, pause and the accuracy of the information when repeating it. And the United States representative shall take all aspects of economic factors into consideration before the negotiations, especially in terms of price, and should consider the overall interests. From the perspective of the Chinese representatives, they should prepare all the materials which are involved in the negotiations before the negotiation. At the beginning of the negotiation, the Chinese delegates could not accept the price that American representatives has offered, but they did not take the way of speaking into account or show the powerful evidence (two years ago, the American company sold the same oven to Hungary at the price of $\$ 950000$ ). They just bargained, resulting in the failure of the negotiation. If there were no farewell meeting, in which Chinese delegates showed the strong evidence, the negotiation would definitely failed at last.

\section{English Questioning Strategy}

In business negotiations, this is an important skill. The negotiators often use this strategy to find out the true intentions of the other party and master the changing trend of their mind. The strategy of asking question can cause the other party's attention and provide a define direction for the two parties, and help you collect the information and transmit your feelings. This strategy can help you make the other party think and guide the trends. Meanwhile, the other side's responds can stimulate the smooth running of the negotiation. Therefore, the attitude of asking question must be sincere, reasonable and pay attention to the other party's thoughts. In particular, you should not blame the other party's personality. Meanwhile, you should not always ask question continuously. You should grasp the language pace and tone and set aside enough time to let the other party think and express their opinions. And you must avoid misunderstanding and making the other party feel bored and unwilling to answer the questions. So, you should pay attention to the manner of asking question in the negotiations.

\section{Use of Open-Ended Questions}

In international business negotiations, the negotiating parties can use open-ended questions to understand the specific circumstances of each other, and get the information they want. For example:

A: What do you think of our proposal?

B: Can't you do better than that?

A: What do you mean by better?

In this example, if the A asked,“Can't you do better than that?”and immediately gave his or her ideas, B will take advantage of the time in considering how to answer A. Besides, A will exposure the bottom line to the opponent. Therefore, A also used the open questions, which cleverly put the ball back to $\mathrm{B}$ and put the $\mathrm{B}$ in the vulnerable condition.

\section{Use of Conditional Questions}

When interests conflict occurred in the negotiation parties, using condition question properly can not only reduce the loss as much as possible, but also get further knowledge of the specific situation of the opponent. For example:

A: We would accept it if you could modify your price.

B: Are you willing to afford the freight if we accept your requirement?

In this case, A obviously wants to get more profits by reducing the price of products, usually B in this case only have two choices: one is to agree, the other is to disagree. But no matter what kind of results, this will make both sides feel sorry for the negotiation, and even affect the long-term 
cooperation in the future. B's answer not only saves some interests for themselves but also avoid hurting the negotiation opponent, which can satisfy both sides.

\section{English Replying Strategy}

A negotiator's level of negotiating will depends on the skills of reply. In normal situations, when you answer the question, you should base on the real condition and answer questions directly.

\section{Use of vague Expression and euphemism}

Vague expression is generally divided into two kinds of expression: one is to reduce the extent of truth or change relatedness, such as: a little, almost, basically etc.; the other is to emphasize that the speaker's words are just based on their own subjective judgment or indirect facts, such as: I'm afraid, maybe, as for me, we guess that, as far as I know etc. In the negotiation, sometimes it is inconvenient or unwise to give some kind of information to the other party, and sometimes the negotiators have to but are unwilling to answer the questions. At these times, using the vague language is very important. We should seldom use these words: inevitable, no doubt, certainly and other absolute words. If you want to refuse the other party and you must do that in a polite way, you can say like that, "In this case, I cannot give you an answer right now. I have to check with my boss and then I will let you know as soon as I get an answer.” By doing so, we can avoid the negotiation impasse.

\section{Other English Language Strategies in Negotiation}

\section{Use of Compliments}

In the early stage of business negotiations, it is difficult for the negotiators to grasp the true intention of the other party and put forward an effective question. So the most important is that you must understand the true intentions and other relevant intentions of the opposite. Applying the negotiating strategy with praise and compliment, we should pay attention to the following items: Firstly, the attitude should be honest and the measure should be appropriate. Secondly, you should respect others'personality and consider the individual's self-consciousness of the other party. Thirdly, you should pay attention to their reaction after being praised. If the person seems very indifferent or impatient, we should stop and change to another topic.

Business negotiation is a difficult process, because it is a psychological warfare. This means that in the process of negotiations, it is crucial to meet the psychological needs of negotiators. If one side only wins the temporary economic interests but hurt the negotiating partner's psychological emotion, the relationship between both sides will weaken or even terminate, leading to the bad results that both parties do not expect. In business negotiations, negotiators wish their products or services can get the praise from the other, their performance or ability could get opponents' recognition or admiration. Therefore, the negotiators should praise the other side properly to meet the needs for dignity. And this can be achieved through the use of compliments. For example:"Mr. Greene, you are quite handy and experienced in bargaining. You do have your own way of persuading people, me as well, into agreeing with your prices. For the business and friendship as well, I accept your prices.” The negotiator here offers proper compliments and meets the opponent's self-esteem needs, which just make the negotiation successful.

\section{Use of Negotiating Partner-Oriented Expression}

Negotiating partner-oriented expression does not only mean changing the expressions "I, we, our, my" into "you and your". Firstly it requires negotiators fully understand the difficulties or the problems that negotiation opponent now face, offer active concern and proposals to express the negotiator's sincerity and get the trust of the other side. In this way, both parties of the negotiation are easier to reach an agreement in the negotiations. For example:

A: I want to take this opportunity to thank you for the time that you spent with me yesterday.

$\mathrm{B}$ : Thank you for spending the time with me yesterday.

In this example, A sentence use "I" as the subject of the sentence, the hearer is placed in the 
subordinate position. While in the B example, the hearer is placed in the center position, this expression, make the listener feel respected and finally reached mutually satisfactory negotiation result.

\section{Conclusion}

With the development of China market economy and the expansion of the opening up policy, especially after entering into WTO and proposing the initiative of "One Belt One Road", China is more and more active in international business and international business negotiations. Therefore Chinese companies and businessmen need to know how to use the universal official languageEnglish and its relevant language skills. Since in international business negotiations, the conditions of both sides, including the factors of product quality, business reputation, technology advantages and other substantial factors play a leading role in cooperation. But as for the external process and form, business negotiation is in fact the process that both parties use language to convey opinions and exchange ideas. Therefore the application of English language skills in international business negotiation just has a decisive influence on the negotiations' process and results.

This thesis studies the application of English language strategies in international business negotiation, explores how business negotiators enhance their own quality, use English language strategies skillfully to eliminate obstacles effectively and achieve their desired goals.

Through the elaboration of the related theory of international business negotiation and business English language characters, we can have a clear understanding of the research object, and realize the importance of using English language skills in international business negotiations in theory. On this basis, combined with the successful or failed cases study, the exploration into the application of the specific English language skills (including statement, replying and questioning skills) in international business negotiations could provide a more vivid and effective guidance for the negotiators to select the appropriate language expression according to different occasions, hence eliminate the obstacles and promote international business negotiation going smoothly, and ultimately achieve their desired goals. It is obviously that the research done in this paper is quite limited; how to use the corresponding language skills flexibly according to the specific cultural differences between different countries still needs to be further explored in theory and practice.

\section{References}

[1] Neil, R. Lawrence, F. 1999.Big future cooperation and competition [M]. Beijing: economic management press.

[2] Roy J. Lewicki. 2006. Mastering Business Negotiation: A Working Guide to Making Deals and Resolving Conflict [M]. New Jersey: Jossey-Bass publishers.

[3] Yuan Bai. 2015. International Business Negotiation [M]. Beijing: The Chinese People’s University Press. 